\title{
Information and Announcements
}

\section{Referesher Course on \\ Contemporary Non-Equilibrium Thermodynamics and Statistical Mechanics}

\author{
20 October - 2 November 2010
}

Sponsored by Indian Academy of Sciences, Bangalore, Indian National Science Academy, New

Delhi and The National Academy of Sciences, India, Allahabad

A Refresher Course on "Contemporary Non-equilibrium Thermodynamics and Statistical Mechanics" for College/ University teachers is being held at the Department of Chemistry, R T M Nagpur University, Nagpur from 20 October to 2 November, 2010. The course will cover topics selected mostly from post-graduate/graduate curriculum in the broad areas of non-equilibrium thermodynamics and statistical mechanics and their applications. The lectures will be followed by problem solving, discussion sessions and home assignments. Prof. D S Ray, Department of Physical Chemistry, IACS, Kolkata is the Course Director and Profs. A A Bhalekar and L J Paliwal of R T M Nagpur University, Nagpur are the Course Coordinators.

Professors David Jou (UAB, Bellaterra, Spain), Ingo Müller (TU, Berlin, Germany), N Sathyamurthy (IISER, Chandigarh), C Dasgupta (IISc, Bangalore), Sunil Nath (IIT, Delhi), D Chowdhury (IIT, Kanpur), B L Tembe (IIT, Mumbai), R S Johal (IISER, Chandigarh), R Venkatesh (BHU, Varanasi), G S Natarajan (LIT, Nagpur), P M Gade (Nagpur University, Nagpur), S S Dhondge (Nagpur University, Nagpur), A A Bhalekar (Nagpur University, Nagpur), D S Ray (IACS, Kolkata) will be the resource persons of the course. Some more resource persons may be added later.

Teachers who wish to participate may write giving bio-data mentioning date of birth, qualifications, teaching experience, and positions held, courses taught to the following:

Prof. A A Bhalekar, Workshop Coordinator, Department of Chemistry, R T M Nagpur University, Amravati Road Campus, Nagpur 440 033, Maharashtra, Tel: (0)9371530535, Email: anabha@hotmail.com

Applicants may also indicate particular topics and problems related to the broad areas indicated above which they would like to get covered or discussed in the Refresher Course to help them improve their delivery in teaching.

Selected outstation participants (up to 20) will be provided with local hospitality and round trip train fare to Nagpur (three-tier AC) by the shortest route. The local participants (up to 10) will also be allowed to participate and provided the necessary support.

Though the course is primarily meant for College/University teachers, research students who wish to participate may also apply.

Last date for registration is 10 August, 2010. 